\title{
Bone Dysplasia: a must-have Atlas for the clinician
}

\author{
Francesca Forzano ${ }^{1}$ \\ Published online: 14 May 2019 \\ (c) European Society of Human Genetics 2019
}

Review of: "Bone dysplasia - an atlas of genetic disorders of skeletal development (fourth edition)"

Edited by: Jürgen W Spranger, Paula W Brill, Christine Hall, Gen Nishimura, Andrea Superti-Furga, Sheila Unger Published by: Oxford University Press, 2018

ISBN: 978-0-190-62665-5

Hardback: $£ 192.50$ / \$295.00

Ebook: $£ 163.67$ / €203.96 / \$251.99

The new edition of this must-have book has finally arrived in store!

Congenital bone disorders are rare conditions affecting the skeleton. There are over 450 different types and altogether they account for a considerable proportion of cases who attend the paediatric and genetic clinics worldwide. Making a specific diagnosis of a bone dysplasia is extremely important for many reasons.

First, reaching the correct diagnosis means that an appropriate management can be planned, depending on the age, from birth to adulthood.

Secondly, genetic counselling can be implemented, including recurrence risk for the offspring and relatives, and to explore options for prenatal surveillance, including preimplantation genetic diagnosis.

Increasingly, it would allow new therapeutic strategies to be explored in light of new developments in the clinical trials arena.

In order to explore this complex terrain of extremely rare disorders, a suitable guide is much needed. This book provides a perfect tool for all clinicians from different fields - whether genetics, paediatric, orthopaedics, radiology or adult medicine - at each level of expertise, to orient themselves and eventually reach a clinical diagnosis.

\footnotetext{
Francesca Forzano

Francesca.Forzano@gstt.nhs.uk

francesca.forzano@nhs.net

1 Clinical Genetics Department, Guy's \& St Thomas' NHS Foundation Trust, London, UK
}

Since the first edition in 1974 there have been many changes and some unvaried characteristics.

The pace of the past edition, which date 1974, 2002, 2012 and 2018, underlines the significant expansion of knowledge in this field over the last two decades, and the pressing need to provide the readership with an updated version. Improvements since the last edition (the third) include description of more conditions, alongside radiographs and clinical images, which are indispensable tools for the clinician.

The chapters are organized in accordance with the International Skeletal Dysplasia Society Nosology of Genetic Skeletal Disorders, 2015 revision, reflecting the evolution in the classification of these conditions over time, which have more recently benefitted from molecular advances.

What has not changed is the format of very concise data sheets for each condition, including information on aetiology, natural history, complications, and differential diagnoses. This makes this Atlas easily consultable, while representing the most complete reference book on genetic bone disorders at present. Richness yet simplicity of usage are key words, and this enviable remit could only be achieved by authors as Spranger, Brill, Hall, Nishimura, Superti-Furga and Unger, who are among the world's leading experts in the field.

Indeed, as Albert Einstein said, 'If you can't explain it simply, you don't understand it well enough'.

This volume will surely be a much valued companion for all the clinicians who deal with bone dysplasias.

Publisher's note: Springer Nature remains neutral with regard to jurisdictional claims in published maps and institutional affiliations.

\section{Reference}

Bonafe L, Cormier-Daire V, Hall C, Lachman R, Mortier G, Mundlos $\mathrm{S}$, et al. Nosology and classification of genetic skeletal disorders: 2015 revision. Am J Med Genet A. 2015;167A:2869-92. https:// doi.org/10.1002/ajmg.a.37365. 